\title{
Aminolysis of Y-Substituted Phenyl 2-Thiophenecarboxylates and 2-Furoates: Effect of Modification of Nonleaving Group from 2-Furoyl to 2-Thiophenecarbonyl on Reactivity and Mechanism
}

\author{
Ik-Hwan Um and Se-Won Min \\ Division of Kano Sciences and Deparment of Chemistw. Ewha Womans Chivensitv. Seoul 120-750. Korea \\ E-mail: ihmià ewhachr \\ Received December 10, 2007
}

\begin{abstract}
Second-order rate constants $(k)$ have been measured for reactions of Y-substituted phenyl 2-thiophenecarboxy lates (6a-h) with morpholine and piperidine in $80 \mathrm{~mol} \% \mathrm{H}_{2} \mathrm{O} / 20 \mathrm{~mol} \% \mathrm{DMSO}$ at $25.0 \pm 0.1^{\circ} \mathrm{C}$. The Bronsted-type plot for the reactions of $6 \mathrm{a}-\mathrm{h}$ with morpholine is linear with $\beta_{l g}=-1.29$. indicating that the reactions proceed through a tetrahedral zwitterionic intermediate $\left(\mathrm{T}^{ \pm}\right)$. On the other hand. the Bronsted-type plot for the reactions of 6a-h with piperidine exhibits a downward curvature, intlying that a change in the ratedetermining step occurs on changing the substituent $Y$ in the leaving group. Dissection of $k$ into nucroscopic rate constants (i.e., $k_{1}$ and $k_{-} / k_{-1}$ ratio) has revealed that $k_{1}$ is smaller for the reactions of $\mathbf{6 a - h}$ than for those of Y-substituted phenyl 2 -furoates $(5 \mathrm{a}-\mathrm{h})$. while the $k_{-} / k_{-1}$ ratio is almost the same for the reactions of $\mathbf{5} \mathrm{a}-\mathrm{h}$ and 6a-h. It is also reported that modification of the nonleaving group from the furoyl (5a-h) to the thiophenecarbonyl (6a-h) does not influence $\mathrm{pK}_{a}^{\circ}$ (defined as the $\mathrm{p} K_{\mathrm{ci}}$ at the center of the Bronsted curvature) as well as the $k_{2} / k_{-1}$ ratio.
\end{abstract}

Key Words : Aminolysis. Bronsted-type plot. Intennediate. Stepwise mechanism. Rate-detennining step

\section{Introduction}

Aminoly'sis of carboxylic esters with a good leaving group often resulted in a curved Bronsted-type plot. i.e.. $\beta_{\text {nuc }}$ decreases from $0.9 \pm 0.2$ to $0.3 \pm 0.1$ as the basicity of the attacking amine increases. Such a curved Bronsted-ty'pe plot has been taken as evidence for a change in the rate-determining step (RDS) ${ }^{1-7}$ The RDS has been suggested to change from breakdown of a tetrahedral zwitterionic intermediate $\left(\mathrm{T}^{ \pm}\right)$to its fomation as the amine nucleophile becomes more basic than the leaving group by 4 to $5 \mathrm{p} K_{\mathrm{a}}$ units. ${ }^{1-7}$

Castro $e t a l$. have reported that the electronic nature of the nonleaving group influences $\mathrm{p} K_{\mathrm{a}}^{\circ}$. defined as the $\mathrm{p} K_{\mathrm{a}}$ at the center of the Bronsted curvature where the RDS changes. ${ }^{6}$ In pyrridinolysis of 2.4-dinitrophenyl $\mathrm{X}$-substituted benzoates (1. $\mathrm{X}=\mathrm{H}, 4-\mathrm{Cl}_{\text {and }}$ a-NO2) they found that the Bronstedtype plot is curved with $\mathrm{p} K_{\mathrm{a}}{ }^{\circ}=9.5$ for the reactions of unsubstituted benzoate but linear for the corresponding reactions of the 4-chloro and 4-nitro derivatives $\left(\mathrm{p} K_{\mathrm{a}}^{0}>\right.$ 9.5) ${ }^{6}$ A similar result has been reported for reactions of 3.4dinitrophenyl X-substituted phenyl carbonates (2) with quinuclidines. ${ }^{7}$ Gresser and Jencks have proposed that an
1

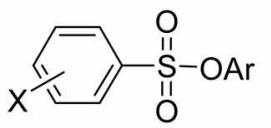

3

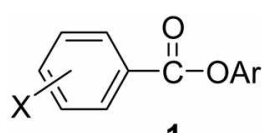

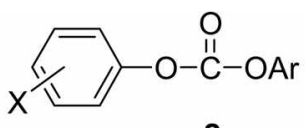

2

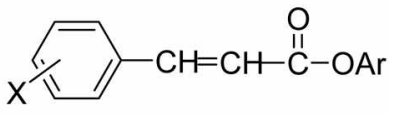

4 electron withdrawing substituent $\mathrm{X}$ in the nonleaving group favors amine expulsion from $\mathrm{T}^{=}$(i.e. the $k_{-}$process in Scheme 1) compared with $\mathrm{ArO}^{-}$expulsion (the $k_{2}$ process in Scheme 1). ${ }^{7}$ Thus. it has been concluded that a stronger electron-withdrawing substituent in the nonleaving group increases $\mathrm{pK}_{\mathrm{a}}{ }^{\circ}$ by decreasing the $k_{2} / k_{-}$, ratio. ${ }^{6.7}$

On the contrary. we have shown that the nature of substituent $\mathrm{X}$ in the nonleaving group affects reactivity but does not influence reaction mechanism for aminolysis of 2.4dinitrophenyl X-substituted benzoates $(1)$ benzenesulfonates $(3)^{8}$ and cinnamates $(4),{ }^{9}$ and hydrolysis of 1 and its thiono analogues. ${ }^{10}$ In all cases. the Hanmett plots were nonlinear. i.e., electron donating substituents in the nonleaving group (e.g.. 4-Me, 4-MeO. 4-NMe? etc.) exhibited negative deviations from the Hanmett plots. ${ }^{58-15}$ Traditionally. such nonlinear Hammett plots have been interpreted as a change in the RDS. ${ }^{\text {l] }}$ However. we have proposed another explanation for the nonlinear Hanmett plots. i.e. stabilization of the ground state (GS) of the substrates through resonance interaction between the electron-donating substituent $\mathrm{X}$ and the carbonyl, thiono carbonyl, and sulfonyl functionalities as illustrated in the resonance structures I and II. $^{58-10}$ This was because the Yukawa-Tsuno plots for the same reactions exhibited an excellent linearity. Furthermore. we have shown that $\mathrm{p} K_{4}^{\circ}$ and the $k_{2} / k_{-1}$ ratio are not influenced by the electronic nature of the substituent $X$ in the nonleaving group for the aminolysis of 1 .'

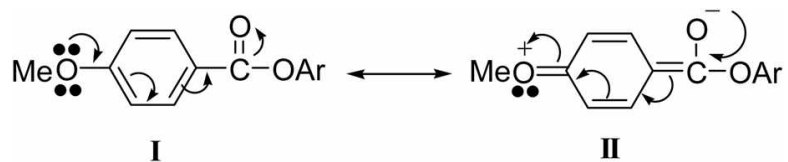




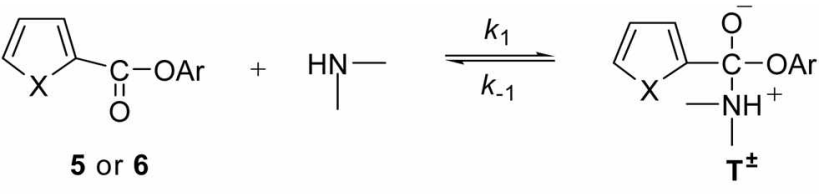

$$
\begin{aligned}
& \stackrel{k_{2}}{\longrightarrow} \quad{ }_{\mathrm{X}}^{\|} \underset{\mathrm{O}}{\mathrm{C}-\mathrm{H}^{+}}+\mathrm{ArO}^{-} \\
& \begin{array}{c}
\mathrm{X}=\mathrm{O}(\mathbf{5}) \cdot \mathrm{S}(\mathbf{6}) ; \quad \mathrm{HN}=\text { morpholine and piperidine } \\
\begin{aligned}
\mathrm{ArO}^{-}= & \mathrm{Y}-\mathrm{C}_{6} \mathrm{H}_{4} \mathrm{O}^{-} \\
& \mathrm{Y}= \\
& 3,4-\left(\mathrm{NO}_{2}\right)_{2}(\mathrm{a}), 4-\mathrm{NO}_{2}(\mathrm{~b}), 4-\mathrm{CHO}(\mathrm{c}), 4-\mathrm{COMe}(\mathrm{d}), \\
& 4-\mathrm{CO}_{2} \mathrm{Et}(\mathrm{e}), 3-\mathrm{Cl}(\mathbf{f}), 3-\mathrm{COM}(\mathrm{g}), 4-\mathrm{Cl}(\mathrm{h})
\end{aligned}
\end{array}
\end{aligned}
$$

Scheme 1

We have extended our study to nucleophilic substitution reactions of Y-substituted phenyl 2-thiophenecarboxylates (6a-h) with morpholine and piperidine to investigate the effect of the leaving-group substituent $\mathrm{Y}$ on reactivity and reaction mechanisn. as shown in Scheme 1. We have also studied the effect of modification of the nonleaving group from the furoyl to the thiophenecarbonyl by comparing the current kinetic data with those reported for the corresponding reactions of $\mathbf{5} \mathbf{a}-\mathbf{h} .^{9 b}$

\section{Results and Discussion}

Reactions of $6 \mathrm{a}-\mathrm{h}$ with morpholine and piperidine proceeded with quantitative liberation of Y-substituted phenoxide and/or its conjugate acid. All reactions in this study obeyed pseudo-first-order kinetics under excess anine nucleophile. Pseudo-first-order rate constants $\left(k_{\text {cbsid }}\right)$ were deternined from the equation $\ln \left(A_{\infty}-A_{t}\right)=-k_{\text {obsd }} t+c$. Correlation coefficients of the linear regressions were usually higher than 0.9995 . The plots of $k_{\text {olsd }}$ vs nucleophile concentrations were linear and passed through the origin. indicating that general base catalysis by the second amine molecule is absent and the contribution of $\mathrm{H}_{2} \mathrm{O}$ and/or $\mathrm{OH}^{-}$ ion from hydroly sis of piperidine (or morpholine) to the $k_{\text {obsd }}$ value is negligible. Thus, the rate equation can be expressed as eq. (1), in which [S] and [ $\left.\mathrm{R}_{2} \mathrm{NH}\right]$ represent the concentration of substrate $\mathbf{6 a - h}$ and anine nucleophile, respectively.

$$
\text { Rate }=k_{\text {olsat }}[\mathrm{S}] \text {, where } k_{\text {obsid }}=k_{\mathrm{N}}[\mathrm{R}=\mathrm{NH}]
$$

Five different nucleophile concentrations were used to determine the second-order rate constant $\left(k_{\mathrm{N}}\right)$ from the slope of the linear plots. It is estimated from replicate runs that the uncertainty in rate constants is less than $\pm 3 \%$. The $k_{\mathrm{N}}$ values determined in this way are summarized in Table 1 and graphically illustrated in Figure 1 as a function of the leaving group basicity.

Reaction Mechanism. As shown in Table 1. the secondorder rate constant $\left(k_{\mathrm{N}}\right)$ for the reactions with morpholine decreases rapidly as the basicity of the leaving aryloxides increases. e.g. it decreases from $10.1 \mathrm{M}^{-1} \mathrm{~s}^{-1}$ to $3.20 \times 10^{-3}$

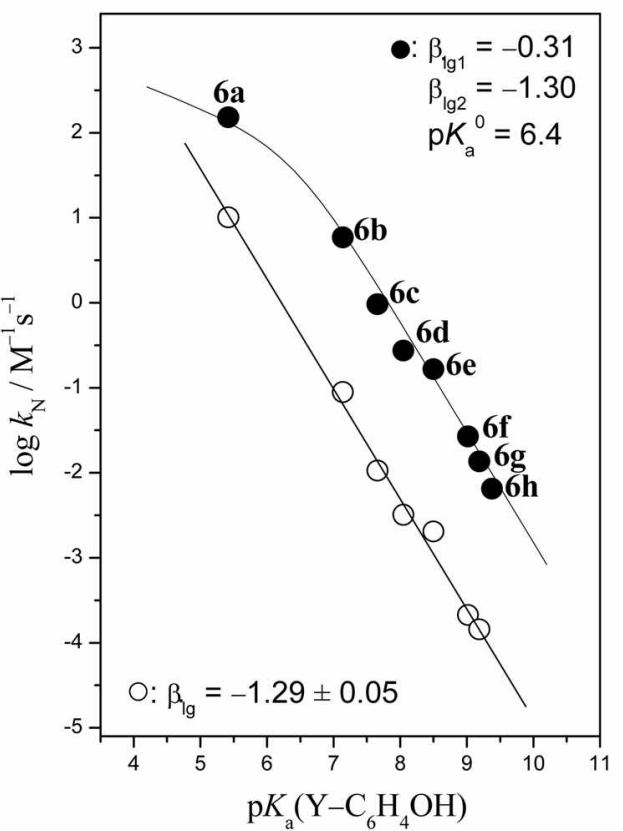

Figure 1. Bronsted-type plots for reactions of $6 \mathrm{a}-\mathrm{h}$ with morpholine (-) and piperidine (•) in $80 \mathrm{~mol} \% \mathrm{H}_{2} \mathrm{O} / 20 \mathrm{~mol} \%$ DMSO at $25.0 \pm 0.1$ " $\mathrm{C}$. The identity of points is given in Table 1 .

Table 1. Summary of Second-order Rate Constants for Reactions of Y-Substituted Phenyl 2-Thiophenecarboxylates (6a-h) with Morpholine and Pipendine in $80 \mathrm{~mol} \% \mathrm{H}_{2} \mathrm{O} / 20 \mathrm{~mol} \%$ DMSO at $25.0 \pm 0.1{ }^{\circ} \mathrm{C}$

\begin{tabular}{ccccc}
\hline \multirow{2}{*}{ Entry } & $\mathrm{Y}$ & $\mathrm{p} K_{\mathrm{a}}$ & \multicolumn{2}{c}{$k \mathrm{~N}^{-1} \mathrm{~s}^{-1}$} \\
\cline { 4 - 5 } & & $(\mathrm{Y}-\mathrm{PhOH})$ & morpholine & piperidine \\
\hline 6a & $3.4-\left(\mathrm{NO}_{1}\right)_{2}$ & 5.42 & 10.1 & 152 \\
6b & $4-\mathrm{NO}_{2}$ & 7.14 & $8.91 \times 10^{-1}$ & 5.89 \\
6c & $4-\mathrm{CHO}$ & 7.66 & $1.06 \times 10^{-1}$ & $9.60 \times 10^{-1}$ \\
6d & $4-\mathrm{COMe}$ & 8.05 & $3.20 \times 10^{-3}$ & $2.74 \times 10^{-1}$ \\
6e & $4-\mathrm{CO}_{2} \mathrm{Et}$ & 8.50 & $2.03 \times 10^{-3}$ & $1.65 \times 10^{-1}$ \\
6f & $3-\mathrm{Cl}$ & 9.02 & $2.12 \times 10^{-4}$ & $2.67 \times 10^{-2}$ \\
6g & $3-\mathrm{COMe}$ & 9.19 & $1.44 \times 10^{-4}$ & $1.36 \times 10^{-2}$ \\
6h & $4-\mathrm{Cl}$ & 9.38 & 4 & $6.50 \times 10^{-3}$ \\
\hline
\end{tabular}

"Too slow to measure $k_{\mathrm{N}}$.

and $1.44 \times 10^{-4} \mathrm{M}^{-1} \mathrm{~s}^{-1}$ as the $\mathrm{p} K_{4}$ of the conjugate acid of leaving aryloxides increases from 5.42 to 8.05 and 9.19 , respectively. A similar result is shown for the corresponding reactions with piperidine, although piperidine exhibits much larger $k_{\mathrm{N}}$ values than morpholine.

The effect of leaving group basicity on reactivity is illustrated in Figure 1. The Bronsted-type plot for the reactions of $6 \mathrm{a}-\mathrm{h}$ with morpholine is linear with $\beta_{\mathrm{lg}}=-1.29$, indicating that the reactions proceed through a zwitterionic tetrahedral intenmediate $\mathrm{T}^{ \pm}$without changing the RDS. On the other hand. the Bronsted-type plot for the reactions of 6a-h with piperidine exhibits a downward curvature. implying that the RDS changes as the leaving group basicity changes.

The RDS of aninoly sis of carboxylic esters has generally been understood to change from breakdown of $\mathrm{T}^{ \pm}$to 
formation of $\mathrm{T}^{=}$as the amine becomes more basic than the leaving ary loxide (or the leaving group is less basic than the attacking anine) by + to $5 \mathrm{p} K_{\mathrm{a}}$ units. ${ }^{1.7}$ Since the $\mathrm{p} K_{\mathrm{a}}$ of the conjugate acid of morpholine was reported to be 8.65 in 20 $\mathrm{mol} \%$ DMSO at $25.0 \pm 0.1^{\circ} \mathrm{C}$, one can expect that a change in the RDS for the reactions with morpholine would occur at $\mathrm{p} K_{\mathrm{a}}$ between 3.65 and 4.65 . which is beyond the $\mathrm{p} K_{\mathrm{a}}$ of 3.4-dinitrophenol (i.e. 5.42). the conjugate acid of the least basic leaving group in this study.

The above argunent can be supported by the curved Bronsted-type plot obtained for the reactions with the more basic piperidine. Since the $\mathrm{p} K_{\mathrm{a}}$ of the conjugate acid of piperidine in $20 \mathrm{~mol} \%$ DMSO at $25.0 \pm 0.1^{\circ} \mathrm{C}$ was reported to be $11.02{ }^{\text {5a }}$ one can expect that a change in the RDS for the reactions with piperidine would occur at $\mathrm{p} K_{\mathrm{a}}$ between 6.0 and 7.0. In fact. the center of the Bronsted curvature is determined to be at $\mathrm{p} K_{\mathrm{a}}=6.4$. Thus. the curved Bronstedtype plot for reactions of $6 \mathrm{a}-\mathrm{h}$ with piperidine can be taken as evidence for a change in the RDS

The nonlinear Bronsted-type plot shown in Figure $I$ can be analyzed using a semiempirical equation (eq. 2). ${ }^{13}$ in which $\beta_{|g|}$ and $\beta_{\mid \mathrm{g} z}$ represent the slope of the Bronsted-type plot at the low and the high $\mathrm{p} K_{\mathrm{a}}$ region, respectively. The center of the Bronsted curvature has been defined as $\mathrm{p} K_{\mathrm{a}}^{\circ}$ (i.e.. the $\mathrm{p} K_{\mathrm{a}}$ where the RDS changes) and the $k_{\mathrm{R}}{ }^{\circ}$ refers the $k_{\mathrm{N}}$ : value at $\mathrm{p} K_{\mathrm{a}}^{\circ}$.

$$
\begin{aligned}
& \log \left(k_{\mathrm{R}} / k_{\mathrm{N}}{ }^{0}\right)=\beta_{\mid \mathrm{gl} l}\left(\mathrm{p} K_{\mathrm{a}}-\mathrm{p} K_{\mathrm{a}}{ }^{0}\right)-\log [(1+\alpha) / 2] . \\
& \text { where } \log \alpha=\left(\beta_{\mathrm{lg} \mid}-\beta_{\lg }\right)\left(\mathrm{p} K_{a}-\mathrm{p} K_{\mathrm{a}}{ }^{\circ}\right)
\end{aligned}
$$

The parameters determined from the fitting of eq. (2) to the experimental points are $\beta_{\text {|g } 1}=-0.31 . \beta_{\text {gg: }}=-1.30$. and $\mathrm{p} K_{\mathrm{a}}{ }^{\circ}=6.4$ for the reactions of $6 \mathrm{a}-\mathrm{h}$ with piperidine. A sumilar result has been reported for the reactions of Ysubstituted phenyl 2-furoates (5a-h) with piperidine, i.e., a curved Bronsted-type plot with $\beta_{\mid g l}=-0.28, \beta_{1 \mathrm{~g}:}=-1.25$. and $\mathrm{p} K_{\mathrm{a}}{ }^{\circ}=6.4$. The $\mathrm{p} K_{\mathrm{a}}^{\circ}$ value of 6.4 determined for the reactions of 6a-h with piperidine is identical to that reported for the corresponding reactions of 5a-h. indicating that the change in the electrophilic center from furoyl to thiophenecarbonyl does not influence the $\mathrm{p} K_{\mathrm{a}}{ }^{\mathrm{O}}$ value.

Dissection of $k_{\mathrm{v}}$ into Microscopic Rate Constants, $k_{1}$ and $k_{2} / k_{-1}$ Ratio. The microscopic rate constants (i.e. $k_{1}$ and $k / k_{-1}$ ratio) associated with the reactions of $6 \mathrm{a}-\mathrm{h}$ with piperidine have been calculated using the method reported by Castro et al $^{13}$ on the assumption that the reactions proceed through a stepwise mechanism with a change in the RDS. The rate equation and the apparent second-order rate constant $\left(k_{\mathrm{N}}\right)$ for the current reactions can be expressed as eq. (3). Eq. (3) can be simplified to eq. (4) or (5). Then. $\beta_{\text {lg } 1}$ and $\beta_{\mathrm{gg}}$ : can be expressed as eqs. (6) and (7), respectively.

$$
\begin{aligned}
& k_{\mathrm{N}}=k_{1} k_{2} /\left(k_{-1}+k_{2}\right) \\
& k_{\mathrm{N}}=k_{1} k_{2} / k_{-1}, \text { when } k_{2} \ll<k_{-1} \\
& k_{\mathrm{N}}=k_{1}, \text { when } k_{2}>>k_{-1} \\
& \beta_{\text {181 }}=\mathrm{d}\left(\log k_{1}\right) / \mathrm{d}\left(\mathrm{p} K_{\mathrm{a}}\right)
\end{aligned}
$$

Table 2. Sunmary of Microscopic Rate Constants, $k_{1}$ and $k_{2} / k_{-1}$ Ratios, for Reactions of Y-Substituted Phenyl 2-Thiophenecarboxy lates $(\mathbf{6 a}-\mathrm{h})$ and 2 -Furoates $(\mathbf{5 a}-\mathrm{h}$, in parentheses) with Piperidine in $80 \mathrm{~mol}^{\%} \mathrm{H}_{2} \mathrm{O} / 20 \mathrm{~mol} \%$ DMSO at $25.0 \pm 0.1^{\circ} \mathrm{C}^{a}$

\begin{tabular}{ccccc}
\hline Entry & $\mathrm{Y}$ & $\mathrm{pK_{ \textrm {a } }}(\mathrm{Y}-\mathrm{PhOH})$ & $k_{1} \mathrm{M}^{-1} \mathrm{~s}^{-1}$ & $10^{3} k_{-} / k_{-1}$ \\
\hline a & $3.4-\left(\mathrm{NO}_{2}\right)_{2}$ & 5.42 & $168(425)$ & $9340(8920)$ \\
b & $4-\mathrm{NO}_{2}$ & 7.14 & $37.7(157)$ & $185(192)$ \\
c & $4-\mathrm{CHO}$ & 7.66 & $17.9(84.7)$ & $56.6(60.0)$ \\
d & $4-\mathrm{COMe}$ & 8.05 & $12.1(77.6)$ & $23.3(25.1)$ \\
e & $4-\mathrm{CO}$ Et & 8.50 & $20.0(114)$ & $8.34(9.18)$ \\
f & $3-\mathrm{Cl}$ & 9.02 & $10.5(54.8)$ & $2.55(2.87)$ \\
g & $3-\mathrm{COMe}$ & 9.19 & $7.87(43.0)$ & $1.73(1.97)$ \\
h & $4-\mathrm{Cl}$ & 9.38 & $5.80(14.8)$ & $1.12(1.29)$ \\
\hline
\end{tabular}

The data in parentheses were taken from ref. $9 \mathrm{~b}$.

$$
\begin{aligned}
\beta_{\text {lg: }} & =\mathrm{d}\left(\log k_{1} k_{2} / k_{-1}\right) / \mathrm{d}\left(\mathrm{p} K_{a}\right) \\
& =\beta_{\text {!g1 } 1}+\mathrm{d}\left(\log k_{2} / k_{-1}\right) / \mathrm{d}\left(\mathrm{p} K_{a}\right)
\end{aligned}
$$

Eq. (7) can be rearranged as eq. (8). Integral of eq. (8) from $\mathrm{p} K_{\mathrm{a}}{ }^{\circ}$ results in eq. (9). Since $k_{2}=k_{-1}$ at $\mathrm{p} K_{\mathrm{a}}{ }^{\circ}$. the term $\left(\log k_{2} / k_{-1}\right)_{\mathrm{p} K K_{1}}{ }^{\circ}$ is zero. Therefore. one can calculate the $k_{2} / k_{-1}$ ratios for the reactions of $6 \mathrm{a}-\mathrm{h}$ from eq. (9) using $\mathrm{p} K_{\mathrm{a}}{ }^{\circ}=6.4$, $\beta_{\text {lgl }}=-0.31$ and $\beta_{\text {lg? } 2}=-1.30$.

$$
\begin{aligned}
\beta_{\mathrm{g} 2}-\beta_{\mathrm{gg} 1} & =\mathrm{d}\left(\log k_{2} / k_{-1}\right) / \mathrm{d}\left(\mathrm{p} K_{a}\right) \\
\left(\log k_{2} / k_{-1}\right)_{\mathrm{p} K_{\mathrm{a}}} & =\left(\beta_{\mathrm{gg} 2}-\beta_{\mathrm{gg}}\right)\left(\mathrm{p} K_{\mathrm{a}}-\mathrm{p} K_{\mathrm{a}}^{\circ}\right)
\end{aligned}
$$

The $k_{1}$ values have been determined from eq. (10) using the $k_{\mathrm{N}}$ values in Table 1 and the $k_{y} / k_{-1}$ ratios calculated above. The $k_{1}$ and $k_{y} k_{-1}$ ratios obtained in this way are summarized in Table 2 together with those reported for the reactions of 5a-h with piperidine for comparison purpose.

$$
k_{\mathrm{T}}=k_{1} k_{2} /\left(k_{-1}+k_{2}\right)=k_{1} /\left(k_{-1} / k_{2}+1\right)
$$

Effect of Modification of Nonleaving Group on Reactivity and Mechanism. Aryl 2-thiophenecarboxylates were reported to be less reactive than aryl 2-furoates toward amines. ${ }^{14}$ Table 2 shows that the $k_{1}$ value is smaller for the reactions of 6a-h than for those of 5a-h. On the other hand, the $k / k_{-1}$ ratio is almost the same for the reactions of $6 \mathbf{a}-\mathbf{h}$ and $\mathbf{5 a}-\mathbf{h}$. Thus, $k_{1}$ is fully responsible for the difference in the reactivity between the furoates $\mathbf{5} \mathbf{a}-\mathbf{h}$ and the thiophenecarboxylates 6a-h.

The effect of leaving group basicity on $k_{1}$ and $k_{2} / k_{-1}$ ratios is illustrated in Figures 2 and 3, respectively. Reactions of 6a-h exhibit better correlation than those of $5 \mathrm{a}-\mathrm{h}$ in the plots of $\log k_{1} \vee \mathrm{p} K_{a}$ (Figure 2). The slopes determined are -0.29 and -0.34 for the reactions of $\mathbf{5} \mathbf{a}-\mathbf{h}$ and $\mathbf{6 a - h}$, respectively, which are small but typical for aminolyses proceeding through rate-determining formation of $\mathrm{T}^{ \pm}$. It is also noted that $k_{1}$ is smaller for the reactions of $\mathbf{6 a - h}$ than for those of Sa-h regardless of the leaving group basicity.

The plots of $\log k_{2} / k_{-1}$ is $\mathrm{p} K_{\mathrm{a}}$ exhibit excellent linear correlations. The slope of the linear plots and the magnitude of the $k-k_{-1}$ ratios are almost identical for the reactions of 5a-h and 6a-h. which is quite contrasting to the reports by Gresser et $a$ l. and by Castro et al. that the $k_{2} / k_{-1}$ ratio is 


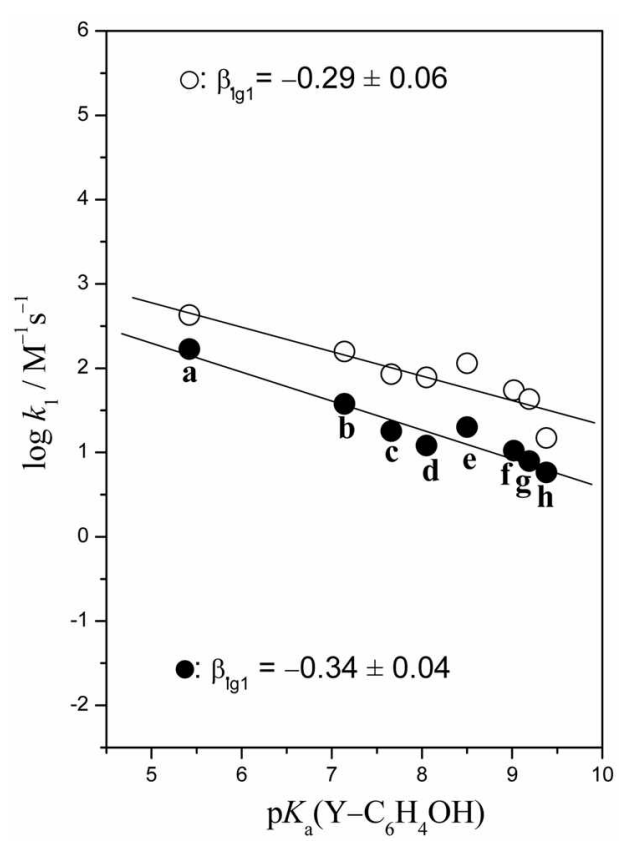

Figure 2. Plots of $\log k_{1} 1 s \mathrm{p} K_{\mathrm{a}}$ of the conjugate acids of the leaving aryloxides for reactions of $5 a-h(1)$ and $6 a-h(-)$ with piperidine in $80 \mathrm{~m} 2 \mathrm{ol} \% \mathrm{H}_{2} \mathrm{O} / 20 \mathrm{mmol} \%$ DMSO at $25.0 \pm 0.1^{\circ} \mathrm{C}$. The identity of points is given in Table 2 .

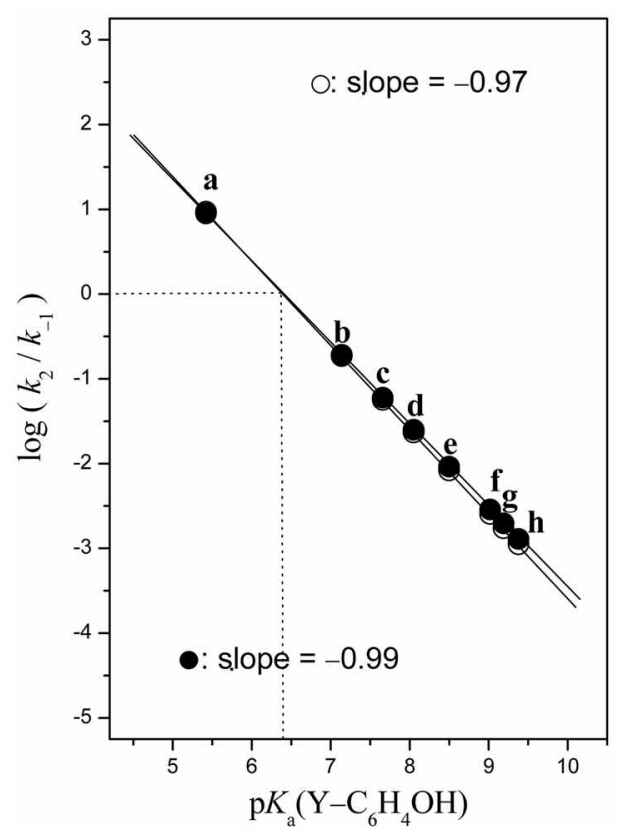

Figure 3. Plots of $\log k_{2} / k_{-1} v s \mathrm{p} K_{\text {il }}$ of the conjugate acids of the leaving aryloxides for reactions of $5 a-h(c)$ and $6 a-h(-)$ with pipendme in $80 \mathrm{~mol}_{\%} \mathrm{H}_{2} \mathrm{O} / 20 \mathrm{~mol} \%$ DMSO at $25.0 \pm 0.1{ }^{\circ} \mathrm{C}$. The identity of points is given in Table 2.

dependent on the electronic nature of the substituent in the nonleaving group. ${ }^{6,7}$ Gresser and Jencks found that the $\mathrm{p} K_{\mathrm{a}}^{\circ}$ value of quinuclidinolysis of 3.4-dinitrophenyl X-substituted phenyl carbonates increases as the substituent $X$ in the nonleaving group of the carbonates becomes stronger electron-withdrawing. ${ }^{7}$ This was attributed to greater stabilization of the transition state (TS) for expulsion of 3,4- dinitrophenoxide ion relative to that for amine expulsion from $\mathrm{T}={ }^{7}$ A similar conclusion has been drawn by Castro et al. for pyridinolysis of 2,4-dinitrophenyl X-substituted benzoates. ${ }^{6}$ It has been argued that an electron withdrawing substituent $X$ decreases $k_{2}$ but increases $k_{-1}$, which results in a decrease in the $k_{2} / k_{\text {-1 }}$ ratio. ${ }^{6,7}$

However, we have proposed that the $k_{2} / k_{-1}$ ratio is independent of the electronic nature of the substituent $X$ in the nonleaving group., ${ }^{5,12}$ This is because both the amine and leaving aryloxide leave with the bonding electrons from the zwitterionic internmediate $\mathrm{T}^{ \pm}$. Accordingly, an electron donating substituent $\mathrm{X}$ would increase both $k_{2}$ and $k_{-1}$ while an electron withdrawing $X$ would decrease both $k_{2}$ and $k_{-1}$. In fact. we have shown that the electronic nature of the substituent $X$ does not influence the $k_{2} / k_{-1}$ ratio in reactions of 2.4-dinitrophenyl X-substituted benzoates with a series of secondary amines..$^{12}$ The same result has been obtained in this study. As shown in Figure 3, i.e., the $k_{2} / k_{-1}$ ratio is almost identical for the reactions of $5 \mathbf{a}-\mathbf{h}$ and $\mathbf{6 a}-\mathbf{h}$. although 2 -furoic acid $\left(\mathrm{p} K_{\mathrm{a}}=3.16\right)$ is a stronger acid than 2-thiophenecarboxylic acid $\left(\mathrm{p} K_{\mathrm{a}}=3.53\right){ }^{15}$

\section{Conclusions}

The current study has allowed us to conclude the following: (1) The Bronsted-type plot for the reactions of 6a-h with morpholine is linear with $\beta_{l 5}=-1.29$. indicating that the reactions proceed tlurough $\mathrm{T}^{ \pm}$. (2) The corresponding reactions with piperidine resulted in a curved Bronsted-type plot, implying that a change in the RDS occurs. (3) The $\mathrm{p} K_{a}^{\circ}$ has been found to be the same for the reactions of $6 \mathrm{a}-\mathrm{h}$ and $\mathbf{5} \mathbf{a}-\mathrm{h}$. which confirms our previous proposal that $\mathrm{p} K_{\mathrm{a}}{ }^{\circ}$ is not influenced by the electronic nature of the substituent $X$ in the nonleaving group. (4) The $k_{1}$ value is smaller for the reactions of $\mathbf{6 a}-\mathbf{h}$ than for those of $\mathbf{5} \mathbf{a}-\mathbf{h}$. while the $k_{2} / k_{-1}$ ratio is almost identical for the reactions of 5a-h and $\mathbf{6 a - h}$. (5) The smaller $k_{1}$ value for the reactions 6 a-h is mainly responsible for their lower reactivity.

\section{Experimental Section}

Materials. Y-Substituted phenyl 2-thiophenecarboxylates $(6 \mathrm{a}-\mathrm{h})$ were readily prepared from the reaction of $\mathrm{Y}$ substituted phenol and 2-thiophenecarbonyl chloride in the presence of triethylamine in anhydrous ether. Their purity was confirmed by their melting points and ${ }^{~} \mathrm{H}$ NMR spectra. Morpholine. piperidine. and other chemicals were of the highest quality available. Due to the low solubility of $6 a-h$ in pure $\mathrm{H}_{2} \mathrm{O}$, aqueous DMSO was used as the reaction medium (i.e. $20 \mathrm{~mol} \% \mathrm{DMSO} / 80 \mathrm{~mol} \% \mathrm{H}_{2} \mathrm{O}$ ). Doubly glass distilled water was further boiled and cooled under nitrogen just before use.

Kinetics. The kinetic studies were perfonned at $25.0 \pm 0.1$ ${ }^{\circ} \mathrm{C}$ with a Scinco S-3100 UV-Vis spectrophotometer equipped with a constant temperature circulating bath for slow reactions (e.g. $t_{1: 2} 10 \mathrm{~s}$ ) or with an Applied Photophysics MV-17 stopped-flow spectrophotometer for fast reactions 
(e.g.. $t_{1: 2}<10 \mathrm{~s}$ ). The reactions were followed by monitoring the appearance of Y-substituted phenoxide ion (or its conjugate acid). All the reactions were carried out under pseudofurst-order conditions in which the amine concentration was at least 20 times greater than that of the substrate.

Typically, reaction was initiated by adding $5 \mu \mathrm{L}$ of $0.02 \mathrm{M}$ of a substrate solution in MeCN by a $10 \mu \mathrm{L}$ syringe into a 10 $\mathrm{mm}$ UV cell containing $2.50 \mathrm{~mL}$ of the reaction medium and the amine. The anine stock solution of ca. $0.2 \mathrm{M}$ was prepared by adding 2 equiv of amine to $I$ equiv of standardized $\mathrm{HCl}$ solution in order to obtain a self-buffered solution. All the transfers of reaction solutions were carried out by means of Hamilton gas-tight syringes.

Products Analysis. Y-Substituted phenoxides (and/or the conjugate acids) were liberated quantitatively and identified as one of the reaction products by comparison of the UV-vis spectra after the completion of the reactions with those of the authentic sample under the same reaction conditions.

Acknowledgments. This work was supported by a grant from KOSEF of Korea (R01-2004-000-10279-0).

\section{References}

1. (a) Jencks, W. P. Catalysis in (Themishy and Enzymologv: MeGrawHill Book Company: New York. USA. 1969: Chapter 10. (b) Page. M. I.: Williams. A. Organic and Bio-organic Mechanisms. Longman: Harlow: U.K. 1997: Chapter 7. (c) Bennett. A. J.: Brown. R. S. In Phnsical Organic Chentistry of Acyl Transfer Reactions. Comprehensive Biological Catahsis Academic Press: New York. 1998; vol. 1.

2. (a) Castro, E. A. Chem Ren, 1999, $99,3505-3524$ (b) Castro. E. A.: Aliaga. M.: Gazitua. M.: Santos. J. G. Tetrathedron 2006. 62. 4863-4869. (c) Castro. E. A.: Campodonico. P. R.: Contreras. R: Fuentealba. P.: Santos. J. G. Leis. J. R.: Garcia-Rio. L.: Saez. J. A.: Domingo, L. R. Tetrahedron 2006, 62, 2555-2562. (d) Castro, E. A.: Gazitua, M. Santos, J. G. J. Org. Chem. 2005. 70. 80888092. (e) Campodonico. P. R.: Fuentealba. P.: Castro. E. A.: Santos. J. G.: Contreras. R. J. Org. Chem. 2005. 70. 1754-1760.

3. (a) Sung. D. D.: Koo. I. S.: Yang. K. Y.: Lee. I. Chem. Phns. Lett. 2006. 432. 426-430. (b) Sung. D. D.: Koo. I. S.: Yang. K. Y.: Lee. I. Chem. Phys Lett 2006, +26. 280-284. (c) Oh. H. K: Oh. I. Y: Sung, D. D. Lee. I. J. Org. (Them. 2005. 70. 5624-5629. (d) Oll. H. K.: Jin, Y. C.: Sung. D. D.: Lee. I. Org. Biomol. Chem. 2005. 3. 1240-1244. (e) Park. Y. H.: Lee. O. S.: Koo. I. S.: Yang. K. Y: Lee. I. Bull. Korean Chem, Soc. 2006. 27. 1865-1868. (f) Hwang.
J. Y.: Yang. K. Y.: Koo. I. S.: Sung. D. D.: Lee. I. Bull. Korean Chent. Soc. 2006. 27. 733-738. (g) Jeong. K. S.: Oh. H. K. Bull. Korean Chem. Soc. 2007. 28. 485-488.

4. (a) Hoque. M. E. U.; Dey, N. K.: Kim. C. K.: Lee. B. S: Lee, H. W. Org Biomol. Chem 2007, 24. 3944-3950. (b) Hoque M. E. U.; Dey. S.: Guha. A. K.; Kim, C. K.: Lee. B. S.; Lee. H. W. d. Org. Chem. 2007. 72. 5493-5499. (c) Hoque. M. E. U.: Dey. N. K.: Guha. A. K.: Kim. C. K.: Lee. B. S.: Lee. H. W. Bull. Korean Chent Soc. 2007. 28. 1797-1802. (d) Hoque. M. E. U.: Lee. H. W. Bull. Korean Chem. Soc. 2007, 28, 936-940.

5. (a) Um, I. H.: Park, Y. M.: Fujio, M.: Mishima, M.: Tsuno. Y. d. Org. Chem. 2007, 72, 4816-4821. (b) Um, I. H.: Lee, J. Y; Ko. S. H.: Bae. S. K. J. Ong Chent 2006. 71. 5800-5803. (c) Un1. I. H.: Kim. E. T.: Park. H. R.: Jeonl. S. E. J. Ong Chem. 2006. 7l. 23022306. (d) Unn. I. H.: Lee. T. Y.: Lee. H. W.: Nagano. Y: Fuiio. M: Tsuno, Y. J. Org. Chem 2005, 70. 4980-4987. (e) Um, I. H.: Kim, K. H.: Park, H. R.: Fujio. M.; Tsuno, Y. J. Org. Chem. 2004, 69. 3937-3942. (f) Um. I. H. Chun, S. M.: Akhtar. K. Bull Konam Chent Soc. 2007. 28. 220)-224.

6. (a) Castro. E. A.: Santander. C. L. J. Org. Chem. 1985. 50.35953600. (b) Castro. E. A.: Valdivia. J. L. J. Ong. Chem. 1986. 51 . 1668-1672. (c) Castro, E. A.: Steinfort. G. B. J. Chem. Soc. Perkin Trans. 2 1983. 453-457.

7. (a) Gresser, M. J.: Jencks, W. P. J. Am. Chem. Soc. 1977.99,69706980. (b) Gresser. M. J. Jencks. W. P. J. Ant. Chent. Soc. 1977.99. 6963-6970).

8. (a) Unn. I. H.: Hong. T. Y.: Seok. J. A. J. Org. Chem. 2005. 70. 1438-1414. (b) Um, I. H; Chun. S. M: Chae. O. M.: Fujio, M: Tsuno, Y. J. Org Chem. 2004. 69, 3166-3172. (c) Um, I. H.: Hong. J. Y.: Kim, J. J.: Chae, O. M.: Bae, S. K. J. Org. Chem. 2003. $68.5180-5185$.

9. (a) Unn. I. H.: Park. Y. M.: Fujio. M.: Mishima. M.: Tsunco. Y. J. Ong Chent 2007. 72. 4816-4821. (b) Unn. I. H.: Akhtar. K: Park. Y. M.; Khan, S. B. Bull. Korean Chem Soc. 2007, 28. 1353 1357.

10. (a) Um. I. H.: Hwang, S. J.; Baek, M. H.: Park. E. J. J. Org. Chem. 2006. 71.9191-9197, (b) Um. I. H.: Han1. H. J.: Baek. M. H.: Bae. S. Y. J. Org Chent 2004. 69. 6365-6370.

11. (a) Carroll. F. A. Perspectives on Sincture and Mechanism in Organic Chemistry: Brooks Cole: New York. 1998; pp 371-386. (b) Lowry, T. H.: Richardson. K. S. Hechanism and Theony in Organic Chemistrv 3rd ed.: Harper Collins Publishers: New York, 1987: pp 143-151. (c) Swansburg. S.: Buncel. E.: Lemieus. R. P. J. An. Chem. Soc. 2000. 122. 6594-6600).

12. Unn. I. H.: Min. J. S.: Lee. H. W. Can. J. Chem. 1999. 77. 659-666.

13. Castro, E. A: Ureta, C. J. Org. Chem 1989. 54, $2153-2159$.

14. Um. I. H.; Lee. E. J.: Lee, J. P. Bull. Korean Chem. Soc. 2002. 23. 381-384.

15. Albert. A. Physical Methods in Heterocyctic Chentistry. Katritzky. A. R.. Ed.: Academic Press: London. 1963: vol. 1. p 44. 